G. ZHAO, D. P. CANTERBURY, A. P. TAYLOR, X. CHENG, P. MIKOCHIK, S. W. BAGLEY, R. TONG* (THE HONG KONG UNIVERSITY OF SCIENCE AND TECHNOLOGY, P. R. OF (HINA)

Synthesis of 2-Arylpiperidines via Pd-Catalyzed Arylation of Aza-Achmatowicz Rearrangement Products with Arylboronic Acids

Org. Lett. 2020, 22, 458-463.

\section{2-Arylpiperidines by Palladium-Catalyzed Addition of Arylboronic Acids to Acylated 2-Hydroxypiperidines}

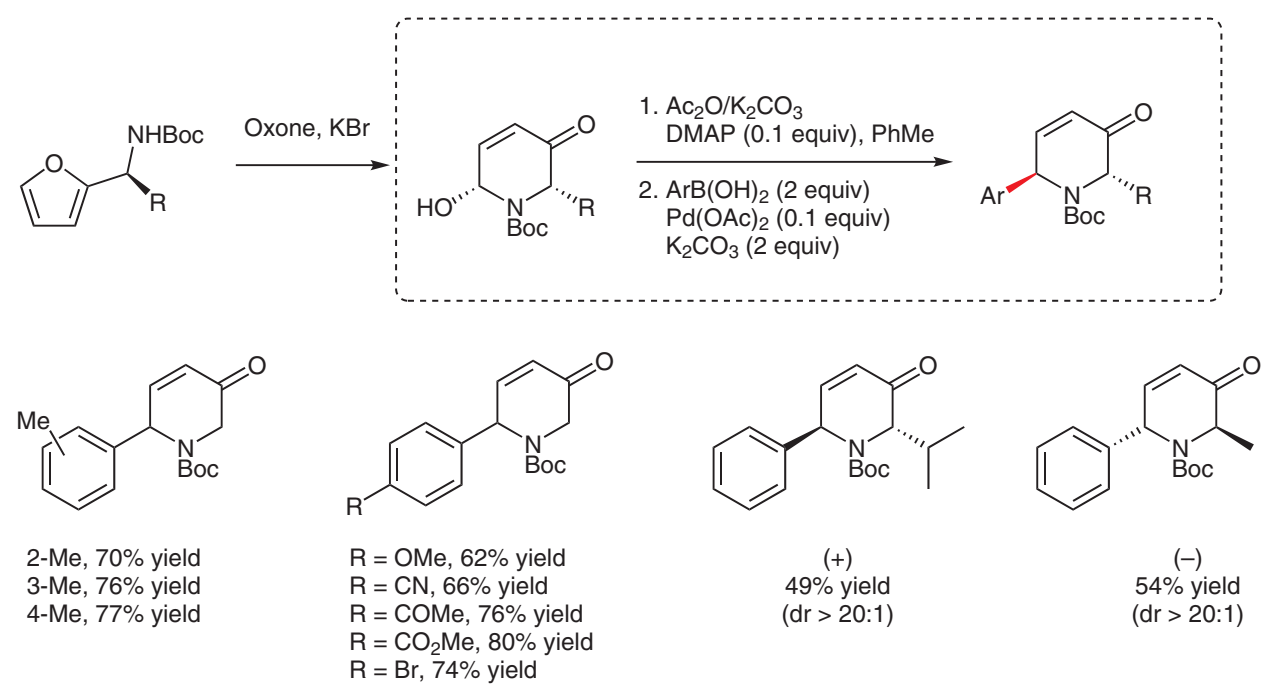

\section{Category}

Synthesis of Heterocycles

Key words

arylpiperidines

aza-Achmatowicz reaction

palladium catalysis arylboronic acids hydroxypiperidines
Significance: A general synthesis of 2-arylpiperidines by one-pot acylation and arylation of 2-hydroxypiperidines was developed. Various substituted phenylboronic acid nucleophiles participate in the reaction to give the corresponding products in good yields. Diastereoselectivity in the arylation process is excellent and provides trans2,6-substituted piperidines. Synthesis of the hydroxypiperidine starting materials proceeds through a classical aza-Achmatowicz rearrangement of fufurylamines initiated by Oxone ${ }^{\circledR}$.
Comment: This method provides piperidine derivates with a variety of functional handles (ketone, alkene, amine) for potential elaboration. Of note is that the synthesis of enantiopure branched furfurylamines provides single 2,6-substituted piperidine isomers. This feature, combined with the existing functionalities on the product, provides valuable access to derivatives with functionalization of every carbon on the piperidine ring. Future work might permit the addition of five- or six-membered heterocyclic nucleophiles in the coupling and might include the exploration of the reactions of substituted furans in this chemistry. 